\title{
WINTER-SPRING STORMS AND THEIR INFLUENCE ON SEDIMENT RESUSPENSION, TRANSPORT, AND \\ ACCUMULATION PATTERNS IN SOUTHERN LAKE MICHIGAN
}

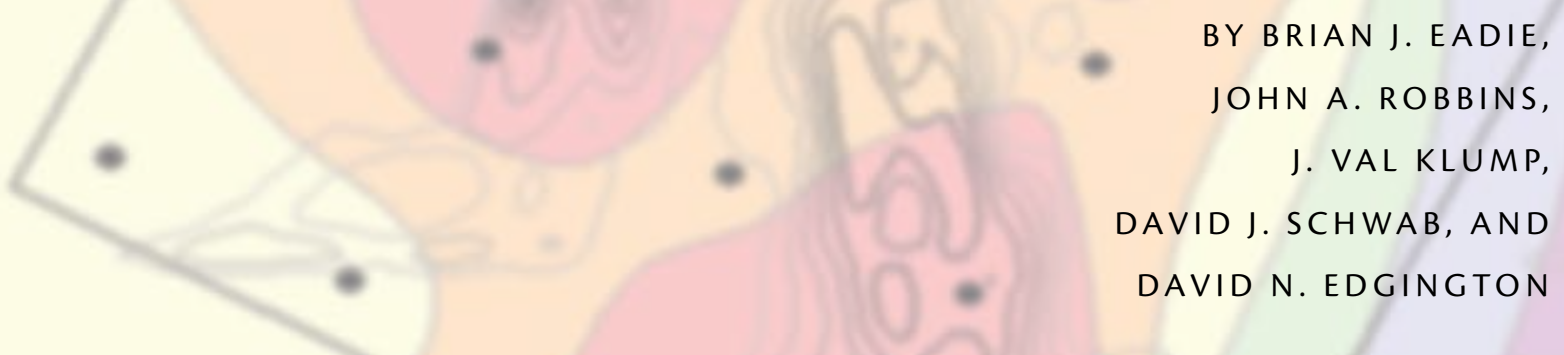


ABSTRACT. The Episodic Events-Great Lakes Experiment was designed to quantify the impacts of major late winter-early spring storms on sediment-water exchange, sediment, and associated constituent transport and resultant influence on well-characterized sediment distributions in southern Lake Michigan. Prior to this project, only very sparse data were available during the late winter-early spring period for any of the Great Lakes, primarily because of strong storms and ice conditions. The observation strategy consisted of moored arrays of current meters, thermistors, and sequencing traps, along with shipboard surveys. In addition, process measurement cruises were conducted along with special cruises for sedimentwater interface sampling using a remotely operated vehicle, particle transformation measurements, and sediment collection. A summary of conclusions include: (1) particles, predominantly from the western shore of the lake, are resuspended and transported in a coastal band toward the major sediment depositional region in the southeastern portion of the lake, (2) transport rates, measured by ${ }^{234} \mathrm{Th}$, are on the order of kilometers per day, (3) the magnitude of resuspended sediments from a single major storm is $1-5 \times 10^{6} \mathrm{~kg}$, larger than annual external input of fine-grained materials to the southern basin, (4) resuspension surrogates based on 50 years of wave data show an interannual variability in major storm events that ranges over an order of magnitude, and (5) trap and ${ }^{7} B e$ evidence indicates that the events appear to be primarily responsible for the complicated sediment accumulation patterns in the southern basin of Lake Michigan. 


\section{PRESENT-DAY MORPHOLOGY}

\section{AND GEOLOGICAL HISTORY}

With a surface area of $57,800 \mathrm{~km}^{2}$ and volume of $4,920 \mathrm{~km}^{3}$, Lake Michigan is the third largest of the North American Laurentian Great Lakes and the sixthlargest lake in the world (Herdendorf, 1990). The lake is surrounded by a relatively small drainage basin of only twice its surface area. The basin developed primarily by ice flow channeling during glacial retreats between 11.8 and 15.5 thousand years ago. With the final retreat of the glaciers and subsequent lowering of water levels, the lake passed through several configurations, finally reaching its current form 4,000-5,000 years ago (Colman and Foster, 1994; Larson and Schaetzl, 2001). The basin continues to rise slowly as a result of isostatic rebound after removal of glacial ice.

The open lake has three principal bathymetric features-southern and northern basins plus a comparatively shallow mid-lake sill $(<100 \mathrm{~m})$ that separates them (Figure 1). The southern

\section{Brian J. Eadie (Brian.Eadie@noaa.gov)} is Scientist Emeritus, NOAA Great Lakes Environmental Research Laboratory, Ann Arbor, MI, USA. John A. Robbins is Scientist Emeritus, NOAA Great Lakes Environmental Research Laboratory, Ann Arbor, MI, USA. J. Val Klump is Senior Scientist, Great Lakes WATER Institute, University of Wisconsin-Milwaukee, Milwaukee, WI, USA. David J. Schwab is Physical Oceanographer, NOAA Great Lakes Environmental Research Laboratory, Ann Arbor, MI, USA. David N. Edgington is Professor Emeritus, Great Lakes WATER Institute, University of WisconsinMilwaukee, Milwaukee, WI, USA. basin is nearly symmetrical, with shelves sloping downward into the 160-m-deep central region. The southern basin has the largest river input, as well as the greatest density of municipal and industrial activities in the lake system. The northern basin is the deepest (maximum sounding $=281 \mathrm{~m}$ ), and the northeastern region has a very complex topography of small ridges, valleys, and islands. The mid-lake high is a relatively shallow sill $(<100 \mathrm{~m})$ that extends outward from the western side of the lake.

\section{SOURCES AND}

\section{CHARACTERISTICS OF}

\section{PARTICULATE MATTER}

Shoreline erosion is the major contributor of sediments to Lake Michigan (Rea et al., 1981) as it is for the other Great
Lakes except for Lake Ontario. For Lake Michigan, erodable bluffs are predominantly along the southern and western shore of the lake. Materials eroded from bluffs comprise approximately $66 \%$ of approximately $1.8 \times 10^{9} \mathrm{~kg} \mathrm{y}^{-1}$ of new particulate material to Lake Michigan, with tributary and aeolian particulate matter contributing about 12\% each (Colman and Foster, 1994). These materials migrate toward depositional basins, primarily along the eastern slope of the lake.

In addition, several types of particulate material are produced within the lake. Biogenic silica, organic matter, and carbonates average about $15-20 \%$ of sediments in the depositional basins. The dominant primary producers are diatoms. These organisms produce

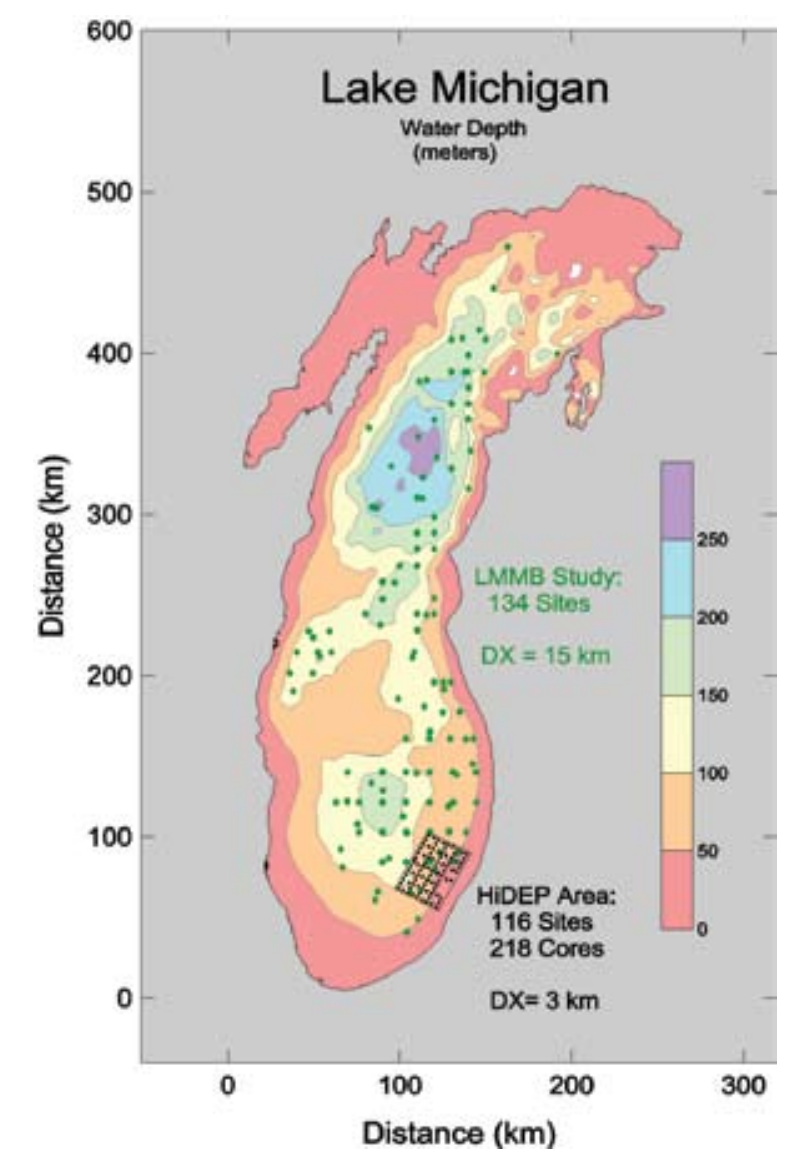

Figure 1. The basins of Lake Michigan. Symbols outside the highest sediment accumulation (HiDep) area indicate locations of 135 box cores collected from 1992 through 1996 as part of the EPA-supported Lake Michigan Mass Balance (LMMB) study. The distribution of sites approximately outlines the extent of corable finegrained deposits in the lake, and corresponds to a spatial resolution of about $15 \mathrm{~km}$. For the intensive HiDep study, a total of 218 cores were collected on a $3-\mathrm{km}$ grid. 
an exoskeleton of amorphous silica in addition to converting dissolved inorganic constituents to particulate organic matter at a rate of approximately $12 \mathrm{mg} \mathrm{C} \mathrm{cm}{ }^{-2} \mathrm{y}^{-1}$, using reported springsummer values of primary production (Fahnenstiel and Scavia, 1987) and half those rates for the other six months. Almost all of the biogenic silica remineralizes back to the dissolved form (Parker et al., 1977) and only about $5 \%$ of the organic matter reaches the sediments (Eadie et al., 1984) where it undergoes further decomposition. There are also three sources of calcium carbonate. A form of calcite precipitates annually from warm surface waters, especially in the southern part of the lake. Ancient carbonates, believed to be predominantly dolomite, erode from the Niagaran reef formations along the southern and western shore and shallows of the lake. Recently, dreissenid (zebra and quagga) mussels are producing a third source of carbonates. Much of the calcite dissolves when the lake cools, but carbonate can reach concentrations of over $25 \%$ in the sediments of the southeastern region of the lake.

\section{LONG-TERM SEDIMENT}

\section{ACCUMULATION PATTERNS} AND FOCUSING

The patterns of long-term sediment accumulation in Lake Michigan are complex. The first substantive efforts to examine the geology of Lake Michigan were conducted by Hough (1958). This study was followed by seismic profiling of sediments to characterize their stratigraphy on geologic time scales (Lineback and Gross, 1972). The most recent stratigraphic unit, the Waukegan Member (age 3,500 y) of the Lake Michigan Formation, is characterized by gray silt in the center and on the eastern side of the southern basin (thickness up to $9.2 \mathrm{~m}$ ) and a brown silt (thickness less than $0.3 \mathrm{~m}$ ) along the western half of the southern basin and the mid-lake high. The Upper Lake Michigan Formation of postglacial sediments is asymmetric (Lineback and Gross, 1972; Cahill, 1981; Foster and Coleman, 1990), with the greatest accumulations found in a series of basins about $20 \mathrm{~km}$ from the eastern shore and decreasing toward the deepest sounding in this basin (Figure 2). These accumulation basins, with sediment thickness up to $20 \mathrm{~m}$, are on the slope.
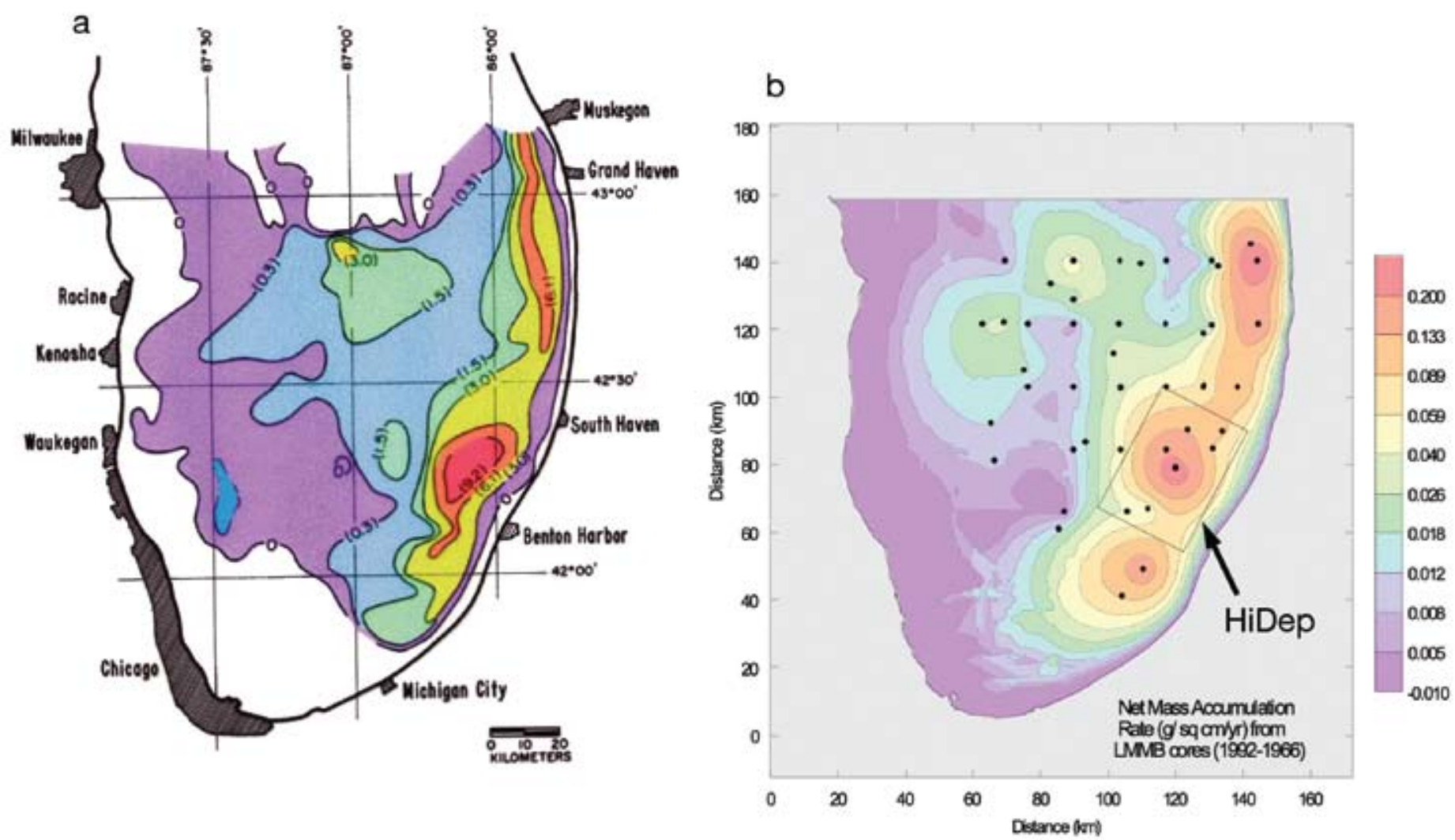

Figure 2. Some characteristics of the sediments in the southern basin. (a) Map of the thickness of the Waukegan Member, representing approximately 3500 years of accumulation (Lineback and Gross, 1972). (b) Sediment accumulation rate $\left(\mathrm{g} \mathrm{cm}^{-2} \mathrm{yr}^{-1}\right)$ based on ${ }^{210} \mathrm{~Pb}\left(\mathrm{t}_{1 / 2}=23 \mathrm{y}\right)$, representing about the last hundred years, thus illustrating the depositional similarity with the long-term accumulation. 
There is essentially no accumulation of sediment in the southwestern portion of the basin, and little along the western side of the lake. There is also a large region in the central part of the lake where sediment has not accumulated. Approximately $30 \%$ of the bottom is accumulating modern sediments while an equal area is nondepositional. The remaining $40 \%$ is considered transitional (Cahill, 1981).

Inventories of radionuclides, or any other constituent with a known source and post-depositional alteration, can be used to estimate a focusing factor. This term is defined as the ratio of the total inventory of constituent in the core to the total amount delivered to the lake and averaged over the lake area. The definition must be modified if the lake is not closed (no significant outflow) with respect to a specific constituent. This method of estimating mean loadings based on atmospherically delivered radionuclides is certainly not valid if there are significant point sources of constituents. Any focusing factor calculation is approximate at best because it assumes that a constituent of interest behaves exactly the same as the focusing estimator. In fact, a recent study by coauthor John Robbins shows that, even for inventories of ${ }^{137} \mathrm{Cs}$ and coproduced ${ }^{239} \mathrm{Pu}$ that entered the lake in an essentially fixed ratio, there are systematic lakewide differences of up to $30 \%$.

\section{MODERN SEDIMENT}

\section{ACCUMULATION}

Modern approaches to the measurement of sediment accumulation rates in Lake Michigan were first applied on a suite of carefully collected gravity cores (Robbins and Edgington, 1975) using profiles of two radionuclides: (1) ${ }^{137} \mathrm{Cs}$, an anthropogenic isotope $\left(t_{1 / 2}=30 \mathrm{y}\right)$, with a well defined source to the Great Lakes (Robbins, 1985), produced in the atmospheric detonation of thermonuclear devices, and $(2)^{210} \mathrm{~Pb}$, $\left(\mathrm{t}_{1 / 2}=22.3 \mathrm{y}\right)$, a natural decay product of ${ }^{238} \mathrm{U}$. The two radionuclides can provide complementary information, because the rate of delivery of ${ }^{210} \mathrm{~Pb}$ is approximately constant, while the delivery of the ${ }^{137} \mathrm{Cs}$ arrived as a pulse, mostly between 1960 and 1963. Both radionuclides have a high affinity for particles, although ${ }^{137} \mathrm{Cs}$ is preferentially associated with clays while ${ }^{210} \mathrm{~Pb}$ is less selective, although it does appear to co-precipitate with calcite during the annual lakewide "whitings" (seasonal precipitation of $\mathrm{CaCO}_{3}$ ). When compared to the steady-state profiles of ${ }^{210} \mathrm{~Pb}$, the pulsed ${ }^{137} \mathrm{Cs}$ data can provide information relating to in-lake processes occurring from multiyear to multidecade time scales. Refined geochronometric models, taking into account various assumptions and limitations, have been developed further over the years (Robbins and Herche, 1993).

Radiometric analysis of eight cores (Robbins and Edgington,1975) yielded a range of linear sediment accumulation rates from $0.07-0.28 \mathrm{~cm} \mathrm{y}^{-1}$ and surface mixing depths (bioturbation) of $0-4 \mathrm{~cm}$. Accumulation rates were shown to correlate well with the thickness of the Waukegan Member. Subsequent analysis of 13 cores from the southern basin provided an estimate of the mean net mass accumulation rate for the basin of $7.0 \mathrm{mg} \mathrm{cm}^{-2} \mathrm{y}^{-1}$, using both stable $\mathrm{Pb}$ and ${ }^{210} \mathrm{~Pb}$. Depth-integrated inventories of ${ }^{137} \mathrm{Cs}$ from 51 cores in the southern basin (Edgington and Robbins, 1976) produced an accumulation map very similar to the high depositional region in southeastern Lake Michigan identified in the Waukegan Member as well as the upper Lake Michigan Formation (Figure 2). Discontinuities in the ${ }^{210} \mathrm{~Pb}$ profiles in two cores from the high depositional region in the southeastern basin were correlated with major storms over the past century. A synthesis of all mass accumulation data results in a lakewide average of $23 \mathrm{mg} \mathrm{cm}^{-2} \mathrm{y}^{-1}$.

Within a decade of its production, ${ }^{137} \mathrm{Cs}$ and (co-produced) ${ }^{239+240} \mathrm{Pu}$ had moved into the depositional region in the southeastern basin, producing patterns similar to long-term accumulation (Edgington and Robbins, 1976). The detailed coring grid in the southeastern depositional region, collected in 1972, was revisited in 1982 to test whether "focusing" of sediments tagged with ${ }^{137} \mathrm{Cs}$ was complete by 1972 or had continued during the subsequent decade (Edgington and Robbins, 1990). Resulting contour plots of the two sets of ${ }^{137} \mathrm{Cs}$ inventories clearly showed that there was a net movement from the edges of the basin, or from outside the basin, into the regions of highest deposition. Thus, although the majority of sediment "focusing" had occurred within the first decade after introduction of the majority of the tracer, the process continued. Sediment trap data, discussed below, has provided further confirmation of sediment remobilization, primarily by storms during the unstratified period.

\section{SEDIMENT MIXING AND DEVELOPMENT OF A RESUS- PENDIBLE PARTICLE POOL}

A tight coupling between contaminated sediments and overlying water exists in lakes and coastal ecosystems through 
the process of sediment resuspension. The long hydraulic residence time of Lake Michigan $(\tau \approx 100 \mathrm{y}$ ), coupled with rapid sorption and settling of particleassociated constituents, ultimately results in large inventories of nutrients and trace contaminants in sediments (Eadie and Robbins, 1987; Bogden et al., 2002; Hornbuckle et al., 2004). Radiotracer studies with ${ }^{239} \mathrm{Pu}\left(\mathrm{t}_{1 / 2}=25,000\right.$ years) and ${ }^{137} \mathrm{Cs}\left(\mathrm{t}_{1 / 2}=30.2\right.$ years $)$ show that $>95 \%$ of these tracers were removed from the water and transferred to sediments within a few years (Edgington and Robbins, 1976; Eadie and Robbins, 1987; Robbins and Eadie, 1991). Although initial removal of particle-reactive tracers from the water is rapid, a residual concentration remains (either on particles, in biota, or in solution) and now diminishes exponentially on a time scale of decades, primarily the result of an annual cycle of sediment resuspension and redeposition that releases constituents from sediments back into the water.

Constituents initially transferred to sediments are homogenized during transport into regional depositional areas where sediments accumulate. Once there, organisms mix the most recently arrived material with older materials, creating a layer corresponding to a decade or more of accumulation. This "resuspendible pool" temporarily resides as a fine-grained veneer of material over otherwise hard, nondepositional substrates (Figure 3). During the years that these materials are part of the resuspendible pool, they constitute a major nonpoint source of nutrients and contaminants to the water column and biota. Studies show a seasonal pattern of elevated particle concentrations and fluxes during the isothermal period, with substantially lower values during the period of stratification (Eadie et al., 1984; Robbins and Eadie, 1991). This

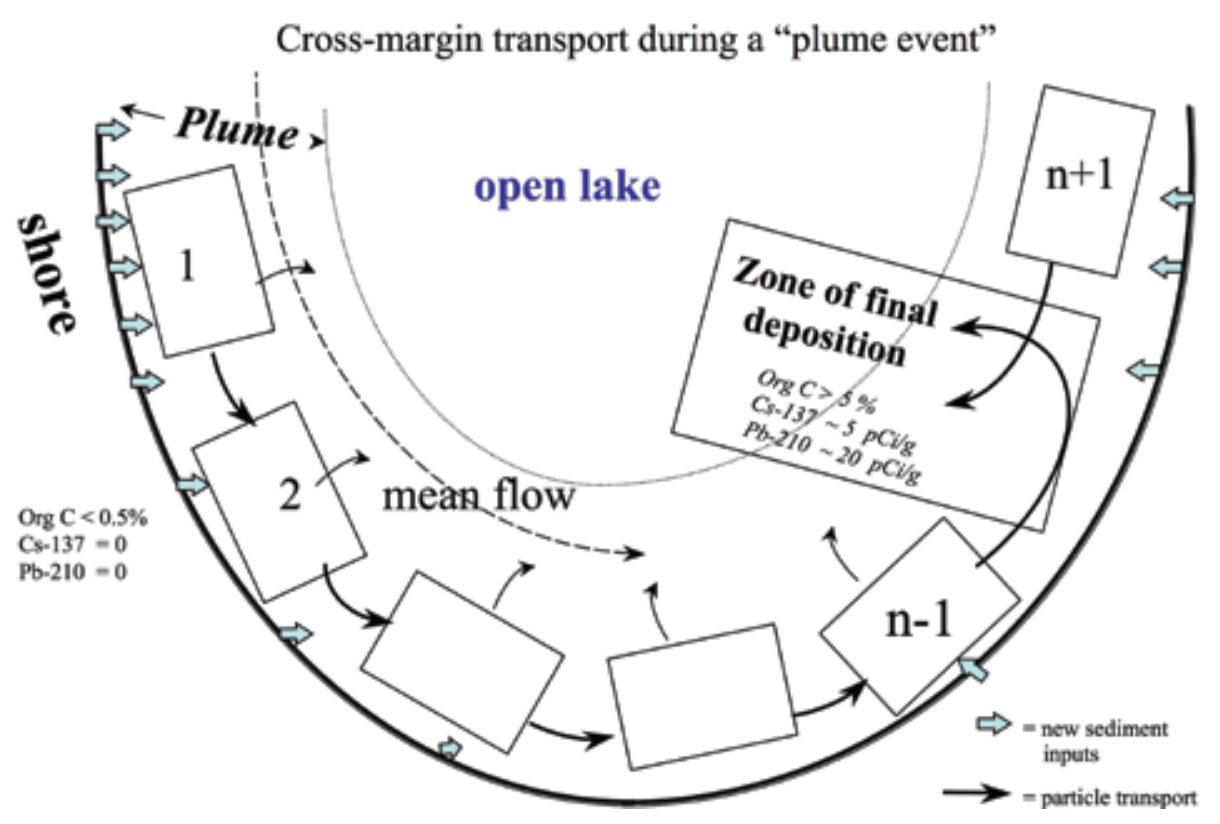

Figure 3. The Episodic Events-Great Lakes Experiment (EEGLE) conceptual model. Sediments from sources predominantly on the western side of the lake are transported primarily in events around the southern basin to the major depositional basin with smaller amounts transported offshore.

observation is consistent with the fact that the most energetic currents and waves occur during storms that are more frequent in the spring and fall than during the summer, and the fact that the energy can penetrate more deeply under near-isothermal conditions.

On the one hand, therefore, deposition and focusing at depth are long-term processes at or near steady state in the lake. The depositional imprint on the bottom in terms of thickness of the mass accumulated indicates that these processes have been relatively constant for at least the last 3,000 years (Figure 2). On the other hand, storm-induced resuspension in the shallow coastal zone of the lake occurs very quickly, very episodically, and has the potential to move a great deal of material within a matter of days to weeks. The answer to the question of how "new" sediments are transported from source to sink (i.e., from where they enter in shallow waters to where they end up in deep waters) and the time scales of that process are fundamental to understanding the fate of riverine, shoreline, and atmospherically derived materials in the lake. The timing of these episodic events could have an influence on the ecology of the system, particularly during the winter-spring transitional period when the spring bloom is initiated, fueled by regenerated nutrients and increasing solar radiation (Chen et al., 2002; Eadie et al., 2002; Ji et al., 2002; Vanderploeg et al., 2007).

\section{THE EPISODIC EVENTS-GREAT} LAKES EXPERIMENT (EEGLE) The Great Lakes Water Quality Agreement between the United States and Canada provides guidelines for management of the Laurentian Great 
Lakes. Over the past several decades, this agreement has been used to define restrictions of phosphorus loads to the lakes and trace organic contaminant (e.g., PCB, DDT) concentrations in fish and other media. The long-term consequences of contaminant inventories in sediments and their dynamics within the lakes are now recognized as critical to ecosystem management. The need to improve our understanding and ability to simulate particle and associated contaminant transport led to the development of a major research program to study the influence of these episodic events in Lake Michigan, the EEGLE project (http://www.glerl.noaa.gov/eegle/ eegle.html). Of particular interest was the fact that the largest events appeared to occur during late winter-early spring (Figure 4), time periods for which there were very few in situ observations (Eadie et al., 1996; Green and Eadie, 2004). It was hypothesized that materials residing in resuspendible pools were biogeochemically transformed within the lake, then redistributed primarily during the thermally unstratified period by a spectrum of energetic events (Chambers and Eadie, 1981; Eadie et al., 1984; Mortimer, 1988; Lesht, 1989; Eadie et al., 1996; Beletsky et al., 2003; Cardenas et al., 2005; Schwab et al., 2006). In the following, we discuss the results of a suite of experiments to explore the validity of this hypothesis.

A main goal of the EEGLE project was to carefully explore and attempt to simulate the consequences of infrequent high-energy events. Our conceptual model (Figure 3) is that temporary deposits of flocculent particles in a thin layer at the sediment-water interface serve a very important function in modulating the movement and characteristics of particles, nutrients, and

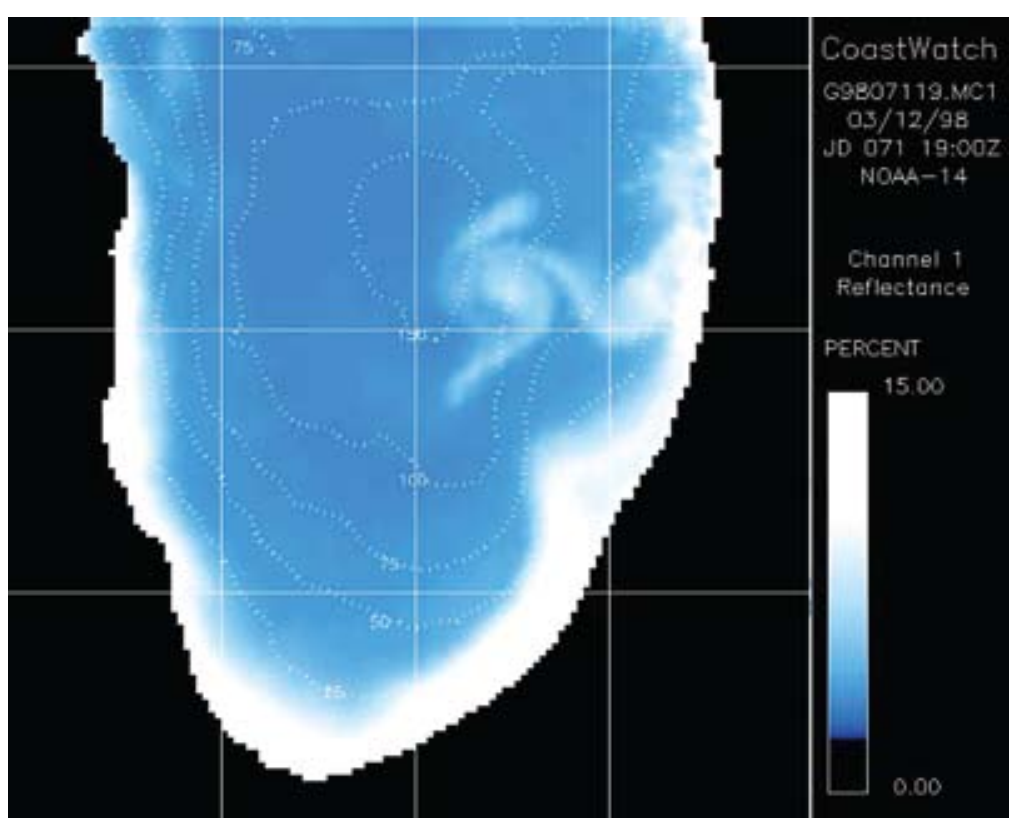

Figure 4. An AVHRR channel-1 satellite image of a plume of resuspended sediments in southern Lake Michigan on March 12, 1998. This event was the largest recorded during the EEGLE project (1998-2002). contaminants between their sources and their ultimate sinks, and during this transition they have a major impact on the lake's ecosystem. This material is recharged by erosional inputs, biogeochemically transformed within the lake, redistributed throughout the year by a spectrum of energetic events, and massively redistributed by major storms and the recurrent coastal plume, driving horizontal and cross-margin transport of suspended particulates (Klump et al., 1996).

\section{A VIEW FROM ABOVE: SATELLITE IMAGES OF COASTAL TURBIDITY PLUMES}

One major event, which appears to occur annually in southern Lake Michigan, is the formation of a late winter-early spring coastal turbidity plume, first documented by Mortimer (1988) from satellite images obtained during the late 1970 s and early 1980s. Intermittent satellite coverage during the EEGLE project revealed the presence of the plume in the visible band (Figure 5) with a clear offshore projection that coincides with the region of maximum sediment accumulation in the lake (Lineback and Gross, 1972; Edgington and Robbins, 1990; Eadie et al., 1996), and with a bathymetric protrusion where topographically steered, storm-induced currents frequently converge to produce significant offshore transport.

Using Coastal Zone Color Scanner images, Mortimer (1988) pointed out several major, basin-scale coastal hydrodynamic phenomena observable in southern Lake Michigan, including front formation and upwelling events, intermittent mobilization and surface transport of sediment resuspended by 
7 March 1999
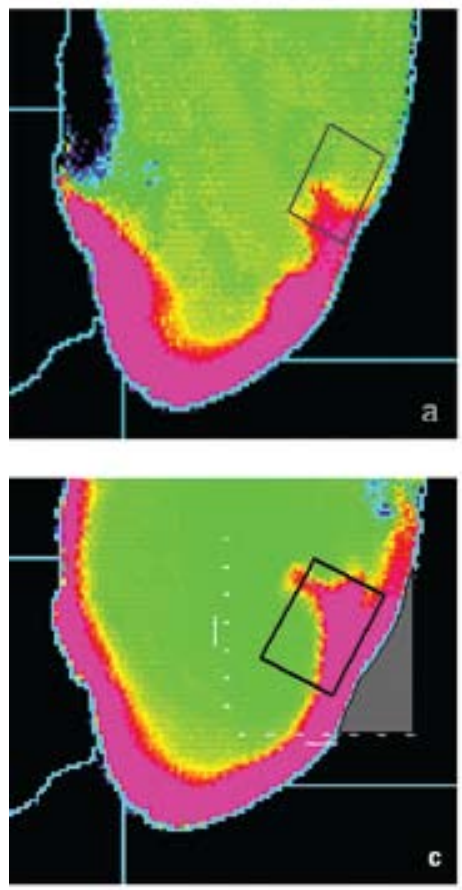

7 March 2001
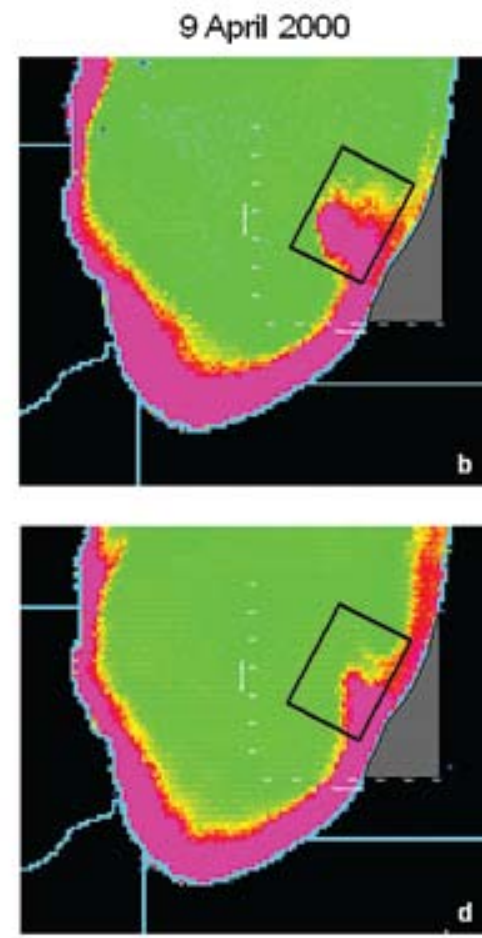

13 February 2002

Figure 5. Satellite observations of major resuspension events for four years associated with the EEGLE project. Although the timing and maximum intensity vary from year to year, the location of the offshore projection is common and consistently develops within the HiDep region. Although these major resuspension events produce dramatic satellite images, it should be noted that resuspension and horizontal movements of particles occur in a quasi-continuous way during the months from about November through April when the lake is isothermal.

storms, and extensive temporary trapping of river- and bluff-derived materials between the shoreline and the offshoremigrating thermal front. Satellite imagery compiled over the last few decades displays the frequent spin-up of high-turbidity coastal plumes of resuspended sediments in response to winddriven wave action. These events occur throughout the year, but are dominated in magnitude by major annually recurrent plume events during the winterspring transitional period, generally early February through early April, prior to the onset of thermal stratification in late May and early June.

In the southern basin of Lake Michigan, alongshore currents are initially driven by wind and steered by bottom bathymetry. The combination of this type of circulation pattern with resuspended materials results in large fluxes from nearshore to offshore. The episodic resuspension and subsequent transport of surface sediments profoundly influences biogeochemical processes in coastal ecosystems. For many constituents in the Great Lakes, the resuspension of surface sediments (which contain large inventories of certain nutrients and contaminants deposited over the past few decades) presently results in much greater fluxes than does resuspension from external inputs (Eadie et al., 1984, 1989; Eadie and Robbins, 1987; Robbins and Eadie, 1991).

\section{RECONSTRUCTING THE}

\section{HISTORY OF PLUME EVENTS}

One task of the EEGLE project was to develop a history of resuspension events to explore their timing, frequency, duration, and intensity. Because storminduced waves are the primary cause of massive sediment resuspension, a one-dimensional sediment resuspension and deposition model for fine-grained sediments was developed and applied to a 45-year period for which data are available (Schwab et al., 2006). The model was calibrated with data from two water-treatment plants (Chicago, Illinois, and St. Joseph, Michigan) for which long-term records of the turbidity from their offshore water intakes are available. The results from the onedimensional model applied at 15 points around the southern basin are averaged to obtain a basinwide turbidity index (Southern Lake Michigan Turbidity Index, SLMTI). A frequency distribution of the turbidity index is presented in Figure 6, which summarizes the modeled history of resuspension events in southern Lake Michigan. It shows a monthly histogram of SLMTI values exceeding 10 and $25 \mathrm{mg} \mathrm{l}^{-1}$ over the 45 -year study period. High-turbidity events are much more likely to occur between October and April than during the rest of the year. There is a slightly lower probability of a turbidity event in February than in January or March, possibly due to the increased probability of more extensive ice cover in February. December had the highest number of days with SLMTI exceeding $10 \mathrm{mg} \mathrm{l}^{-1}$, but the days for which SLMTI exceeded $25 \mathrm{mg} \mathrm{l}^{-1}$ were more uniformly distributed among January, March, November, and December. Analysis indicates that 
large resuspension events in southern Lake Michigan are usually caused by a strong cyclone passing to the east of the lake (Schwab et al., 2006). The most likely time of the year for this type of storm to occur is November to March. On average, there is one event per year with SLMTI above $25 \mathrm{mg} \mathrm{l}^{-1}$ and each event typically lasts about three days. There is also some indication that events have occurred more frequently since the late 1980s as the number of winter storms has increased and there has been less ice cover.
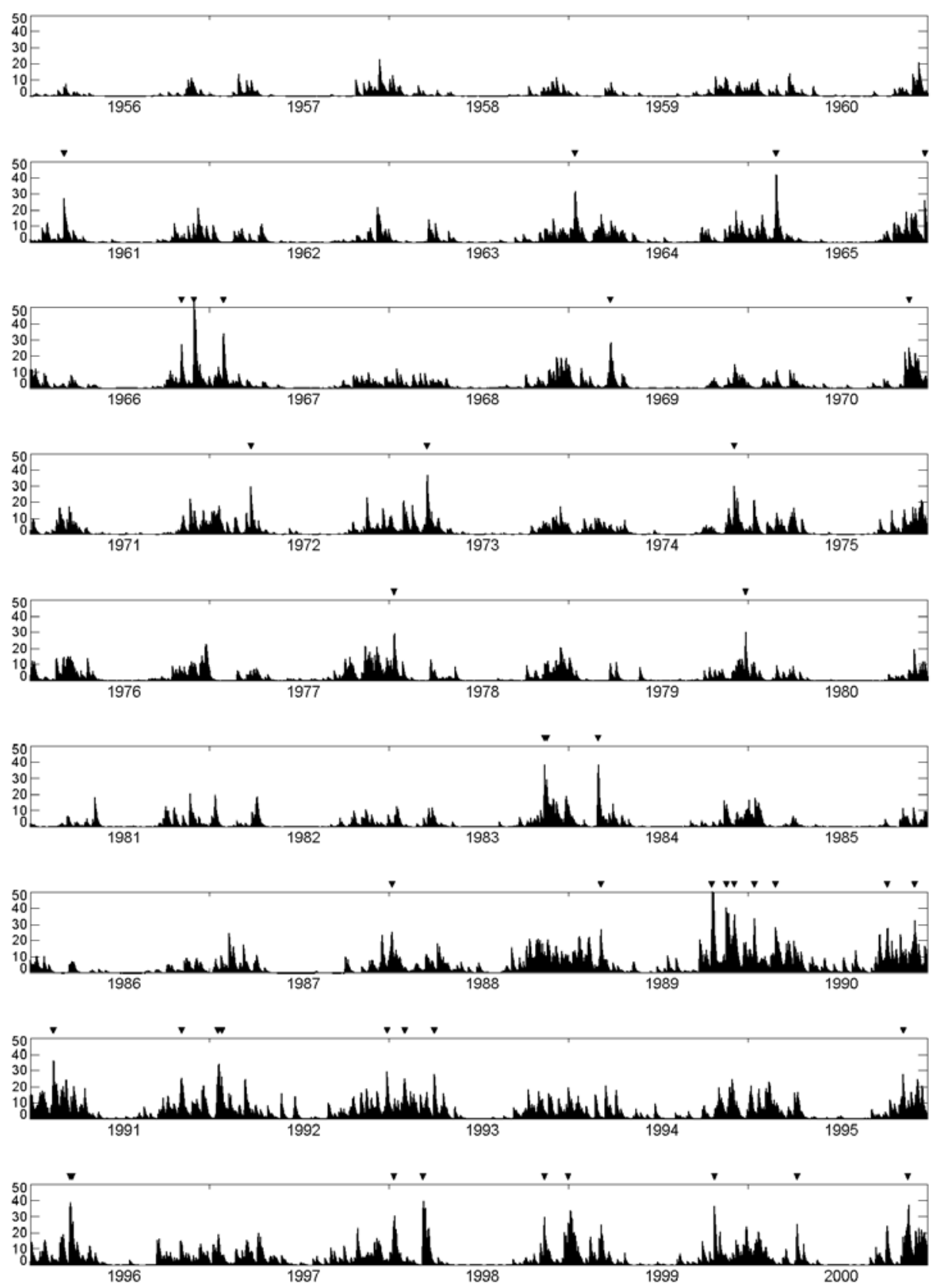

Figure 6. Southern Lake Michigan Turbidity Index (SLMTI) for 1956-2000. Triangles indicate episodes with SLMTI > 25. In addition to the seasonal variability showing maximum storm intensity in spring and fall, there appears to be a longer-term variation showing more frequent and more intense storms in the 1990-2000 period than in earlier intervals.

MASSIVE SEDIMENT

RESUSPENSION DURING

\section{EPISODIC EVENTS}

Throughout the EEGLE project, experiments were conducted to measure mass fluxes of particulate matter during episodic events and to place them in a longer-term context. Particle settling and resuspension processes have been examined in Lake Michigan through the use of sediment traps since the mid 1970s (Eadie et al., 1984). Cylindrical traps, designed for conditions in the Great Lakes (Bloesch and Burns, 1980; Muzzi and Eadie, 2002) are moored at selected depths to intercept materials settling to the bottom. Traps provide an efficient tool for collection of integrated samples of settling materials for detailed analysis. Measuring the mass collected allows calculation of the gross downward flux of particulate matter and associated constituents. A mean particle-settling rate is calculated as the ratio of mass flux to ambient suspended solids concentrations defined as the mean of values obtained at start and end of deployment. From late December through early June, Lake Michigan is virtually isothermal and well mixed. Average fluxes during this period are high throughout the water column. During the stratified period (June-December), the upper half of the water column becomes isolated from the large inventory of materials in the sediments, although episodic mixing does occur during upwellings.

Average particle settling velocities also show substantial differences between the two thermal periods (Eadie and Robbins, 2005). During the unstratified period, the time of major resuspension events, both upper water column and benthic nepheloid layer (BNL) settling 
velocities average $5 \mathrm{~m} \mathrm{~d}^{-1}$. The BNL is a near-bottom region of the water column where turbidity is elevated. During the stratified period, these calculated settling velocities in the epilimnion $\left(0.5-1 \mathrm{~m} \mathrm{~d}^{-1}\right)$ agree with those required to model the long-term behavior of fallout radiotracers (Robbins and Eadie, 1991). Settling velocities estimated for the BNL $\left(5 \mathrm{~m} \mathrm{~d}^{-1}\right)$ show clearly that frequent recharging of the $\mathrm{BNL}$ is required in order to maintain its observed persistence.

During the EEGLE program, sequencing traps were deployed at several locations in the southern basin. These cylindrical traps (Figure 7) have an inner diameter of $20 \mathrm{~cm}$ and an aspect ratio of $8: 1$ above the funnel. A computer- controlled carousel contains 23 60-ml polyethylene bottles, which rotate under the funnel at preprogrammed intervals. Cylindrical traps have a high collection efficiency in low-current lake environments and have proved satisfactory in many lake studies (Bloesch and Burns, 1980; Eadie et al., 1984). Figure 8 illustrates the locations for a five-year record of collections at trap depths of $30 \mathrm{~m}$ below the surface and $5 \mathrm{~m}$ above the bottom at two sites. The mid-lake station (\#12) has a total depth of $160 \mathrm{~m}$, while the nearshore station (\#24), located directly over the highest sediment accumulation in the lake (HiDep, see Figures 1 and 2), is 55-m deep. Also shown is the turbidity measured at the
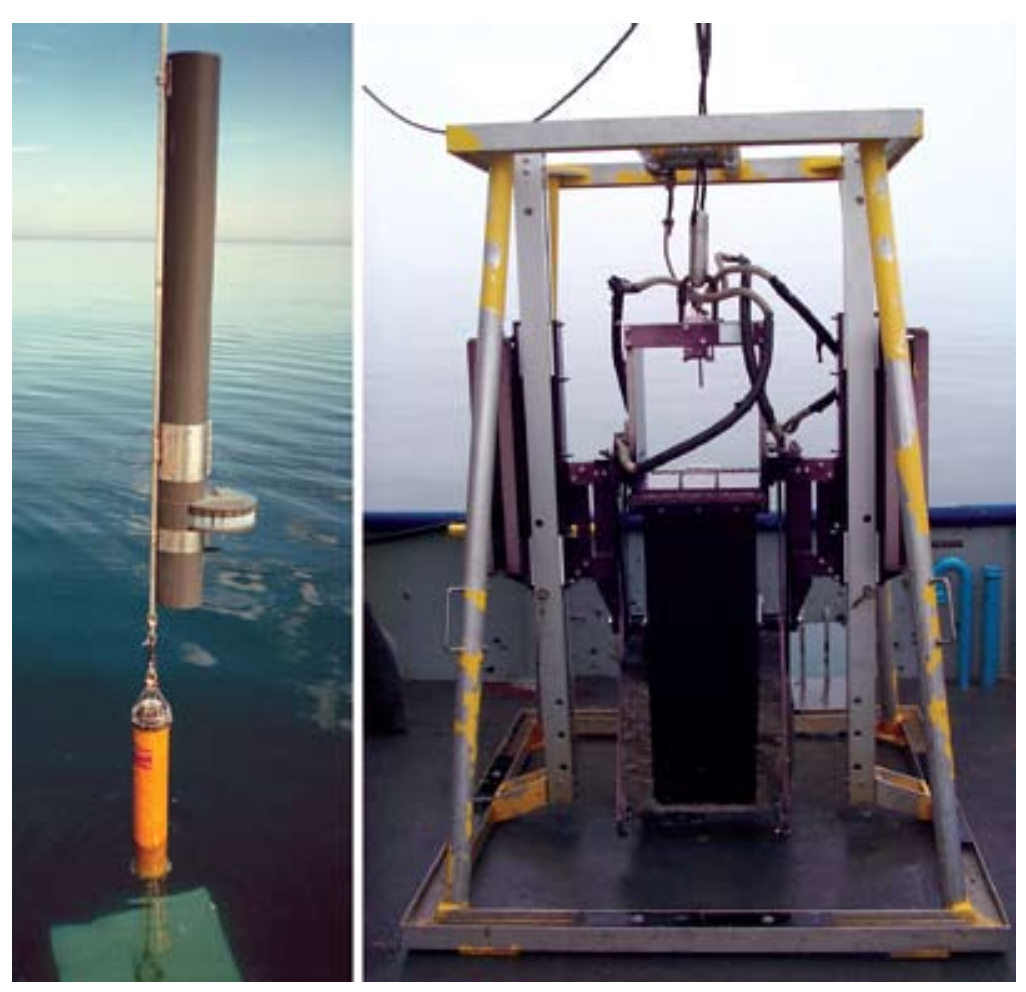

Figure 7. On the left is the sequencing sediment trap used in the EEGLE sampling (for details see Muzzi and Eadie, 2002). The trap is approximately 2-m tall with a carousel of 23 preprogrammed (for sample-collection intervals), prepoisoned collection bottles. On the right is the box corer employed in sediment collection. This device collects a sediment sample approximately $25 \times 25 \times 89 \mathrm{~cm}$ and produces minimal disruption of the sediment-water interface. It is large enough to subsample replicate cores for analysis from the same collection. water intake for St. Joseph, Michigan, located $7 \mathrm{~km}$ offshore. The shaded areas in the figure represent the period when the lake was isothermal, or thermally unstratified. During the unstratified period of 1998, the largest storm recorded during the EEGLE project (see Figure 4) is clearly reflected in the water intake and all traps, and is also seen in the 2001 data. In contrast, the major resuspension events of 1995 and 2000 resulted in high fluxes in the nearshore trap, but not in the offshore trap. Offshore transport occurred as seen in the satellite images (Figure 5), but the overall destination of the resuspended materials is clearly different. The 2000 case is further discussed in the modeling section.

The major storm periods dominate the mass fluxes for traps located at $30 \mathrm{~m}$ below the surface at both sites, often accounting for over $70 \%$ of the total annual flux for the year. Although traps located at $5 \mathrm{~m}$ above the bottom also show a correlation between mass flux and water intake turbidity/storm event, the overall contribution from the events is a smaller fraction of the annual mass flux at these sites. Trap evidence supports the synoptic satellite information that the episodic events are important in the seasonal and episodic delivery of sediments to the HiDep region, and intermittently to the transport of resuspended sediments from nearshore to offshore.

\section{NEARSHORE PARTICLE TRANSPORT DURING EPISODIC EVENTS}

An investigation of the ${ }^{238} \mathrm{U} /{ }^{234} \mathrm{Th}$ parent/daughter pair in the nearshore environments of Lake Michigan shows that short-lived, naturally occurring 


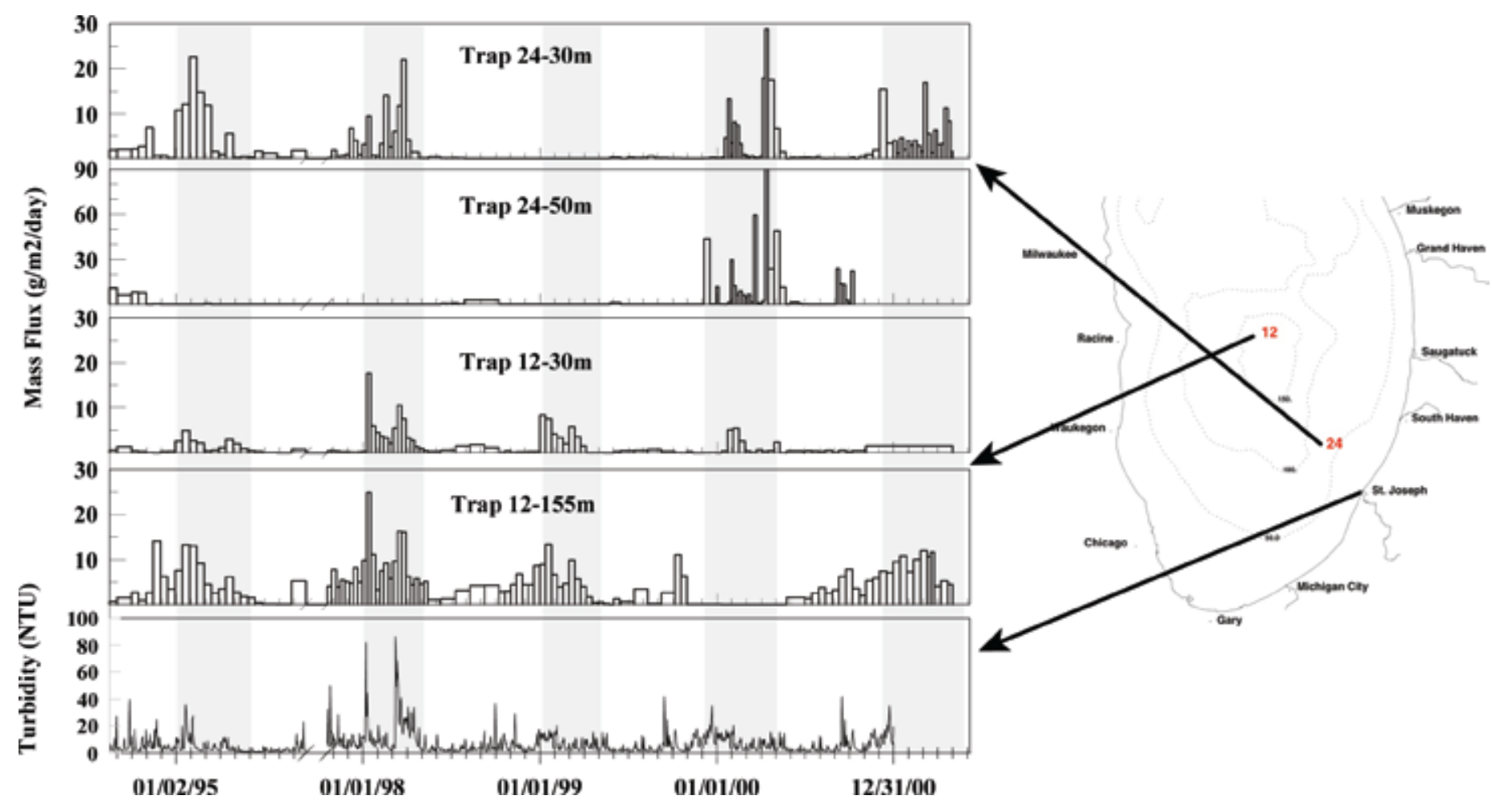

Figure 8. Sediment fluxes as recorded in sequencing sediment traps for five years at two locations. Station T24 coincides with the location of highest recorded sediment accumulation, while T12 represents the center of the southern basin. The light and gray-banded intervals represent the thermally stratified and unstratified periods, respectively. The St. Joseph water intake is located $5 \mathrm{~km}$ offshore at a depth of $7 \mathrm{~m}$. Although large fluxes are recorded at the HiDep location (24) for each year (except 1999 due to trap failure), the offshore trap only records very large events for two of the four years and the water intake for only one of the years. Nearshore-offshore transport varies significantly among years. See Figure 5 for satellite images corresponding to maximum events for each year.

radionuclides are useful in determining the time scales of sediment transport processes on the order of days to weeks. Although ${ }^{238} \mathrm{U}$ occurs in soluble forms, its daughter ${ }^{234} \mathrm{Th}$ has a very high affinity for particles and is rapidly scavenged. The activity of dissolved ${ }^{234} \mathrm{Th}$ is only $\sim 1 \%$ of that supported from the ${ }^{238} \mathrm{U}$ activity of Lake Michigan water, which is essentially constant at $230 \pm 20 \mathrm{dpm} \mathrm{m}^{-3}$. Within these waters, the disequilibria between ${ }^{234} \mathrm{Th}\left(\mathrm{t}_{1 / 2}=24.1\right.$ days $)$ and its parent ${ }^{238} \mathrm{U}$ are generally large, with water-column depletions of ${ }^{234} \mathrm{Th}$ ranging from 0 to $87 \%$ with a median value of 66\% (Waples et al., 2004), comparable to productive or shallow marine systems (Moran et al., 2003). Departures from secular equilibrium, therefore, are driven almost entirely by the transport and settling of particles, whose residence time calculated from the distribution of activities within the water column ranges from 3.7 days to greater than 100 days, with a median value of about two weeks (13.7 days). The temporal, seasonal dynamics of ${ }^{234} \mathrm{Th}$ in the nearshore, including residence times, settling velocities, and mass fluxes, is closely related to the wave climate (Waples et al., 2004). In the absence of net permanent accumulation within the nearshore, mass inputs of sediments must be transported cross margin and exported to the deeper offshore depositional basins of the lake. Using a temporally integrated average of the median ${ }^{234} \mathrm{Th}$-based nearshore mass flux requires this export to be approximately $1.35 \times 10^{9} \mathrm{~kg} \mathrm{y}^{-1}$, or $\sim 18 \mathrm{mg} \mathrm{cm}^{-2} \mathrm{yr}^{-1}$ over the $7500 \mathrm{~km}^{2}$ depositional zone of the southern basin (Waples et al. 2004), an accumulation rate that is essentially identical to that derived from the mean sedimentation rate determined by ${ }^{210} \mathrm{~Pb}$ geochronologies (Robbins and Edgington, 1975).

Although little or no permanent burial occurs in the nearshore, significant masses of fine-grained particles $(<63 \mu \mathrm{m})$ reside temporarily on hard bottoms or within the upper few millimeters of well-sorted sands and gravel. Inventories collected by vacuuming this "benthic dust," using a remotely operated vehicle (ROV)-deployed sampler (Figure 9), generally range from $>0.2$ to $<6 \mathrm{~kg} \mathrm{~m}^{-2}$ with a median 
of $\sim 1 \mathrm{~kg} \mathrm{~m}^{-2}$ (Klump et al., 2003) and trending to higher masses along the eastern reaches of the nearshore zone as the bottom transitions to sands and silty sands that entrain and trap an increasing mass of fine grain particles. Wind- and wave-driven resuspension episodically injects these particles back into the overlying water where they are advected in a counterclockwise fashion following the mean circulation depicted in physical models (Schwab, 1983; Beletsky et al., 2003; Lee et al., 2007).

Subsequent sediment inventories of ${ }^{234} \mathrm{Th}$, therefore, episodically tend to increase from $<0.5 \mathrm{dpm} \mathrm{cm}^{-2}$ to $>1.5 \mathrm{dpm} \mathrm{cm}^{-2}$ along this path from west to east, resulting in ${ }^{234} \mathrm{Th}$ inventories that range from deficiencies of up to $30 \%$ to excesses of three times that supported from the ${ }^{238} \mathrm{U}$ parent in the overlying water (Figure 10). ${ }^{234} \mathrm{Th}$-calculated apparent particle residence times in the water column are generally longer on the western side of the basin, up to several weeks in some cases, often decreasing to less than a few days on the "downstream" eastern end of this particle transport conveyor belt. The observed distribution of excess ${ }^{234} \mathrm{Th}$ may be explained by the import of ${ }^{234} \mathrm{Th}$ from a source area "upstream" of the receiving area (i.e., excess ${ }^{234} \mathrm{Th}$ is focused from one region to another) (e.g., Buesseler et al., 1994; Smoak et al., 2000). To focus ${ }^{234} \mathrm{Th}$ and produce the deficits and excesses in the ${ }^{234} \mathrm{Th}$ inventories observed, the transport time along this gradient must be more rapid than the time scale for decay. Focusing is a function of the relative size of both source/sink areas and the relative observed "downstream excess" and "upstream deficit." For a deficit of $20 \%$, and an excess of $50 \%$, the areal source- to-sink ratio would have to exceed a factor of about four to five for estimated transport times to be on the order of kilometers per day, in keeping with sediment transport velocities observed in bottom tripod deployments at the 20-m-deep location (Lesht, 1989).

Particle export from the nearshore is also rapid. Immediately following a major resuspension event in April 1999, ${ }^{234} \mathrm{Th}$ exceeded supported activities everywhere in the nearshore, ranging from a ${ }^{234} \mathrm{Th} /{ }^{238} \mathrm{U}$ ratio of 1.37 in the western reach to $>2.0$ in the east. Within a month, all excess ${ }^{234} \mathrm{Th}$ had been lost, and ${ }^{234} \mathrm{Th} /{ }^{238} \mathrm{U}$ ratios fell to an average of 0.8 (Figure 11). The resulting mass transfer estimated from the change inventory and the mean particle activity of suspended matter $\left(\sim 70 \mathrm{dpm} \mathrm{g}^{-1}\right)$ yielded a mass export approaching $3 \times 10^{8} \mathrm{~kg}$ of sediment and $7 \times 10^{6} \mathrm{~kg}$ of organic matter within five to six weeks.
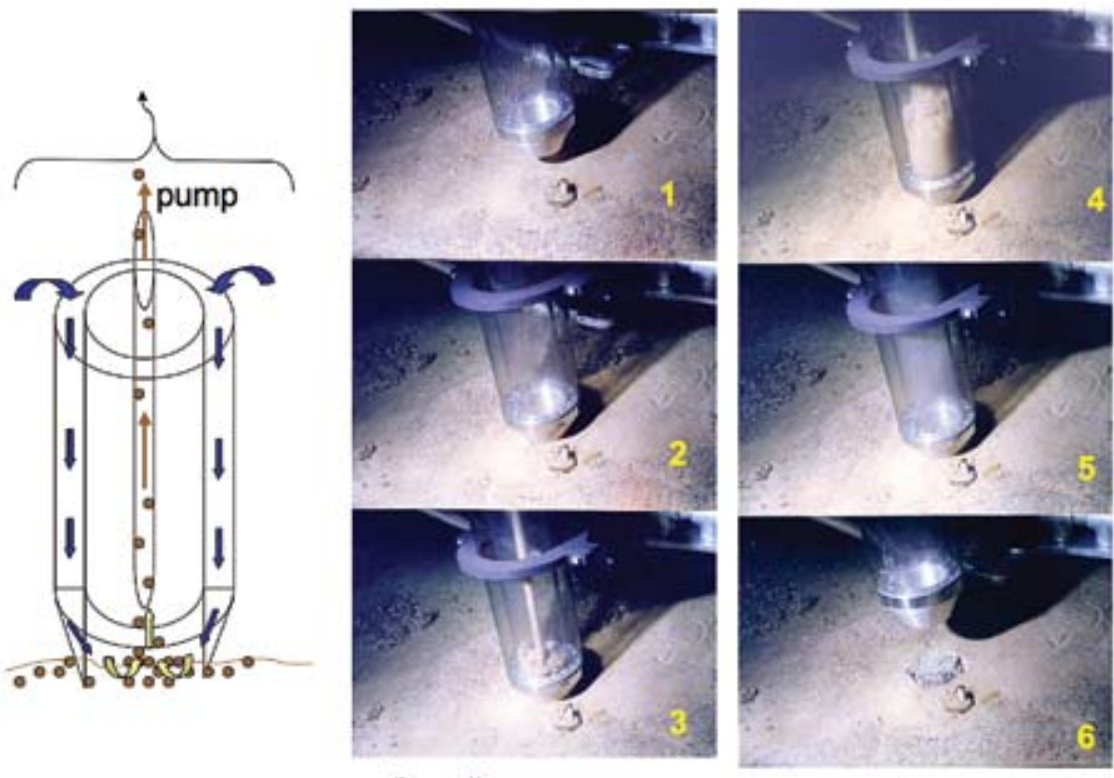

Sampling sequence

Figure 9. "Resuspendible" samples in uncorable, nearshore regions were collected using the interface sampler (depicted) controlled from a remotely operated vehicle (Klump et al., 2003). The sequence shows the collection procedure, from gentle insertion, to maximum "suspension," then pumping until no further sediment is "suspendible." 


\section{${ }^{234} \mathrm{Th} /{ }^{238} \mathrm{U}$ ratios in coastal Lake Michigan}

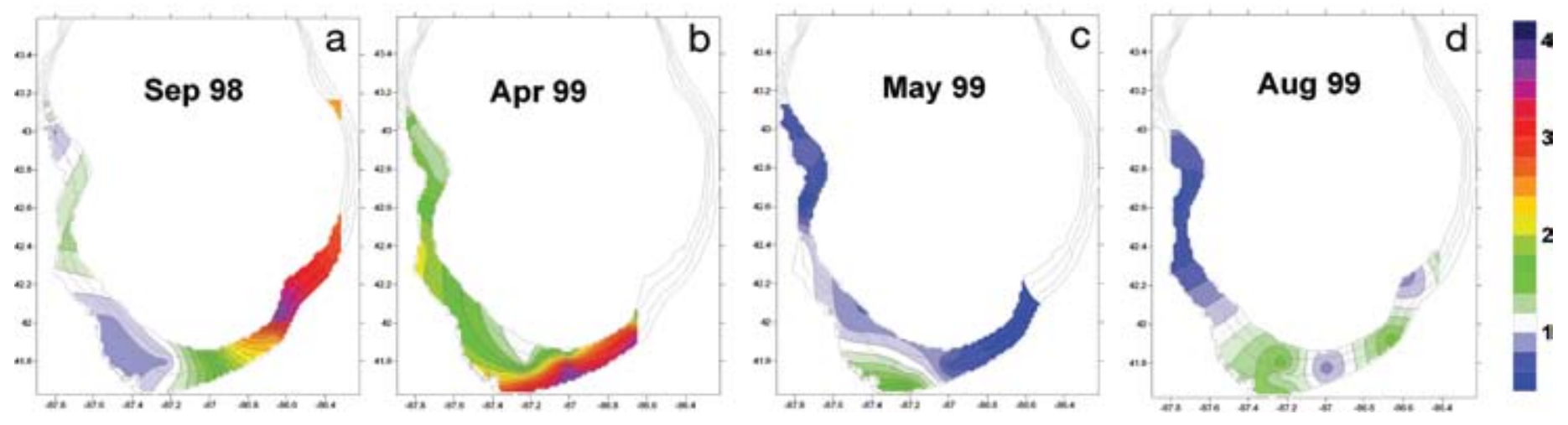

Figure 10. Inventories of excess ${ }^{234} \mathrm{Th}$ show a pattern consistent with alongshore transport and focusing of sediments in the nearshore of the southern basin of Lake Michigan in response to episodic resuspension events. (a) September $1998:{ }^{234} \mathrm{Th} /{ }^{238} \mathrm{U}$ ratios indicate a slight depletion of ${ }^{234} \mathrm{Th}$ relative to its ${ }^{238} \mathrm{U}$ parent along the western shore, trending to a significant excess along the eastern shore. (b) April 1999: ${ }^{234} \mathrm{Th}$ is in excess everywhere within the nearshore, with $\mathrm{Th} / \mathrm{U}$ ratios ranging from 1.3 to $>3.0$ following a major resuspension event, and indicating the import of material from zones external to the region shown. (c) May 1999: Within weeks, this excess has completely disappeared, a loss of activity from the nearshore zone of $\sim 1.3 \times 10^{13} \mathrm{dpm}$ and a mass equivalent to $>240,000$ MT of sediment transported offshore. (d) August 1999: Following the relatively calm summer months, secular equilibrium appears to reestablish itself with Th/U ratios hovering around 1.0. Mass storage also increases, and the accumulation of new material in the nearshore by late August has risen to $\sim 10^{9} \mathrm{~kg}$ since May. For such gradients in Th/U disequilibria to arise, transport must be rapid enough to focus excess ${ }^{234} \mathrm{Th}$ before it decays via its 24.1 -day half life. Alongshore transport on the order of kilometers per day is consistent with observed bottom-current-driven sediment transport observations, with the mean transport predicted by hydrodynamic models incorporating particle advection (Schwab et al., 2000) and with simple box model estimates for ${ }^{234} \mathrm{Th}$ focusing. From recent work by coauthors J Val Klump and David N. Edgington with James T. Waples of the University of Wisconsin-Milwaukee, and Kent A. Orlandini of Argonne National Laboratory, Argonne, Illinois

An EEGLE study was undertaken to determine if a net buildup of particles occurred during late winter episodic events (including the annual plume development), over an area of maximum sediment accumulation.

The HiDep study area (Figures 1 and 2) was established as a region for high-resolution sediment coring because of its distinctive features: (1) uncommonly high rates of sediment accumulation on geologic time scales (3500 yr), (2) high accumulation rates in recent times (e.g., $100 \mathrm{yr}$ ), (3) strong horizontal concentration gradients of sand-size particles, and (4) strong gradients in recently determined distributions of near-surface silt. In this area, the inventory of ${ }^{137} \mathrm{Cs}$ tracks closely with the modern accumulation rate (Figure $3 b$ ), and trap studies show that huge downward fluxes of material occur in the region during resuspension events (Figure 8). Not surprisingly, the area is also distinguished by its relation to satellite images of surface water reflectance (Figure 5) that reveal offshore excursions of turbidity that consistently veer into the HiDep area.

The amounts of naturally occurring ${ }^{7} \mathrm{Be}\left(\mathrm{t}_{1 / 2}=53.4 \mathrm{~d}\right)$ adsorbed to sediments in the area at times before and after the late winter resuspension event that produced a turbidity plume intruding into the southeast corner of the HiDep area on March 7, 1999 (Figure 5a), were measured as inventories of ${ }^{7} \mathrm{Be}$ (in $\mathrm{dpm} \mathrm{cm}^{-2}$ ) from box cores collected on a grid (from 28-39 sites) during four separate occasions from September 1998 through June 1999. ${ }^{7} \mathrm{Be}$ is produced in the atmosphere by cosmic rays and delivered to Lake Michigan at a seasonally varying rate (Robbins and Eadie, 1991). In the lake, the radionuclide is rapidly and strongly adsorbed to clays, clay-sized particles, and organic matter (Hawley et al., 1986). Deposition rates during the period of core collections varied from a minimum during the winter months of about $60 \mathrm{dpm} \mathrm{m} \mathrm{m}^{-2} \mathrm{~d}^{-1}$ to a maximum during the summer of about $220 \mathrm{dpm} \mathrm{m}^{-2} \mathrm{~d}^{-1}$. The time-dependent average inventory of ${ }^{7} \mathrm{Be}$ in the lake was calculated as the integrated deposition rate corrected for radioactive decay (i.e., the standing crop). Maximum inventory in the lake was about $1.6 \mathrm{dpm} \mathrm{cm}^{-2}$ in September 1998 and a minimum of about $0.8 \mathrm{dpm} \mathrm{cm}^{-2}$ in March 1999. Sediment inventories of ${ }^{7} \mathrm{Be}$ were normalized to the lakewide average at the time of core collection, thereby correcting for seasonal variations in loading. This step resulted in values for ${ }^{7} \mathrm{Be}$ focusing factors (FF in percent). 

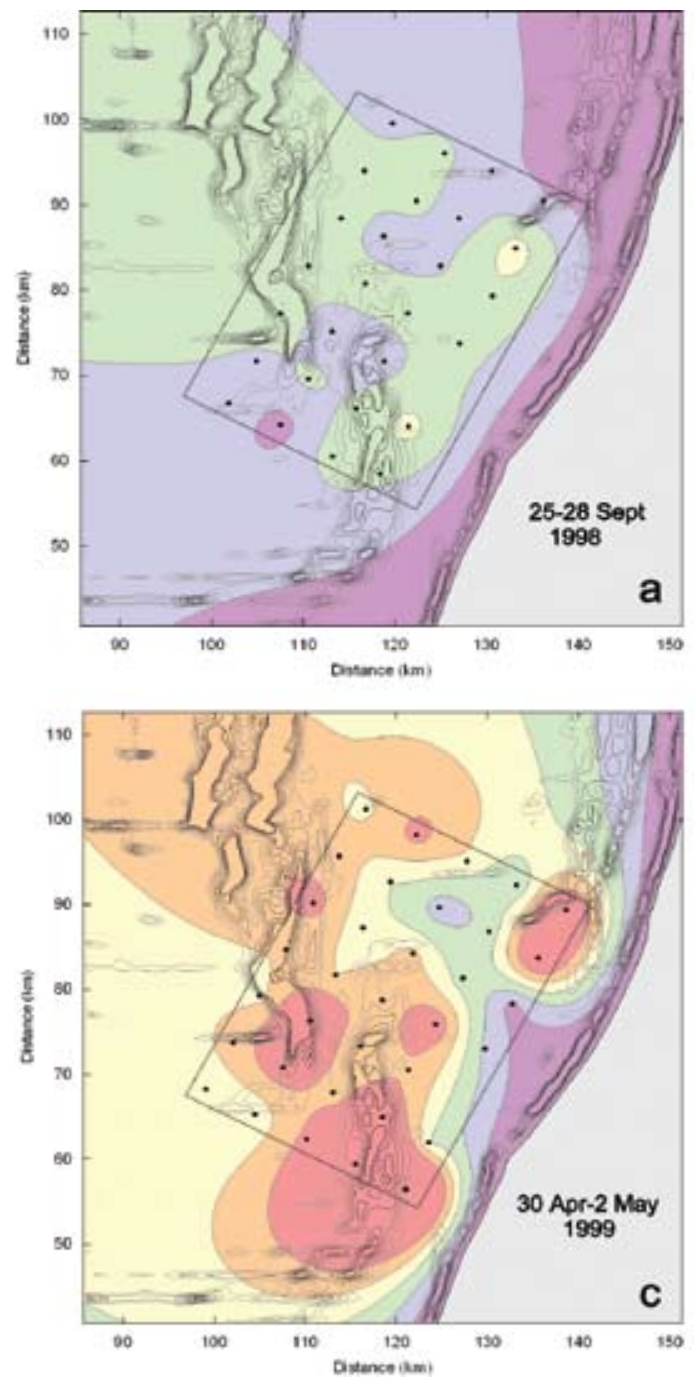

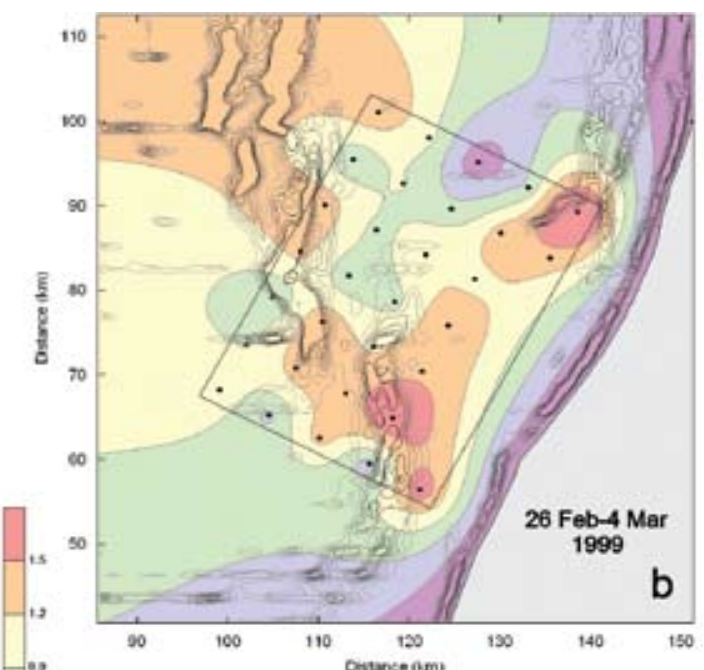

.

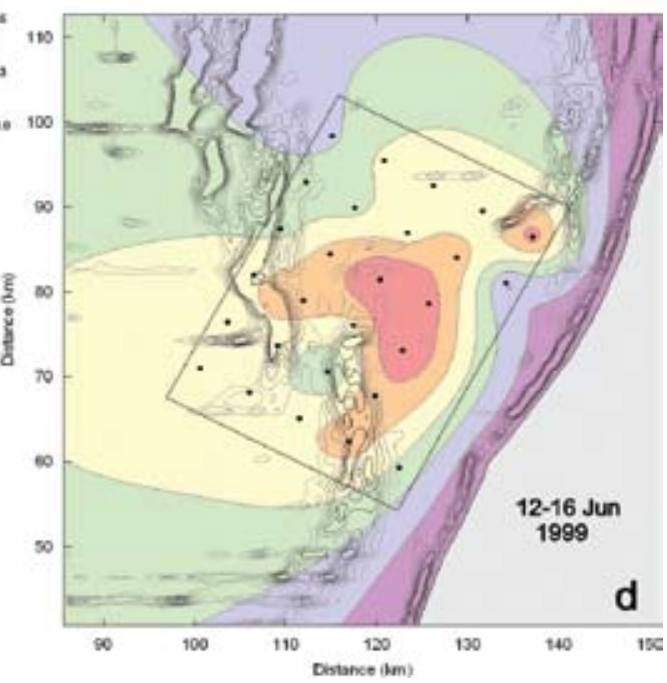

Figure $11 .{ }^{7} \mathrm{Be}$ focusing factor (FF). (a) Pattern in late September 1998. When the lake is thermally stratified, the radionuclide is inefficiently transferred to sediments. Resulting FF is low and comparatively uniform. (b) By late February, the lake had been well mixed for several months. As a result, coupling of atmospheric loading of ${ }^{7} \mathrm{Be}$ to the lake and accumulation in sediments is strong. The FF pattern has intensified, tends to be located in the southeastern area of HiDep, but is patchy. The major resuspension event occurred three days after the end of this collection period. (c) This pattern lasted for 53 days (i.e., one half life of ${ }^{7} \mathrm{Be}$ ) after the event. There is a strong FF (up to 2.0) and a clearly defined path through the area that resembles the plume image. (d) During the final period in June, the lake has restratified. The FF pattern no longer resembles plume patterns. Highest FFs are located in the vicinity of the maximum sediment accumulation in HiDep.
The first survey took place at the end of September 1998 (Figure 11a), about 5.5 months before the March event. The magnitude and pattern of the focusing factor reflects the effect of lake stratification on transfer of ${ }^{7} \mathrm{Be}$ to sediments. Little $(\mathrm{FF}<40 \%)$ resides in sediments toward the end of the period of summer stratification. The spatial distribution is essentially uniform and unrelated to sediment accumulation patterns. Using near-bottom traps, Robbins and Eadie (1991) showed that at a 100-m site in Lake Michigan during the period of thermal stratification, bottom sediments were completely isolated from the atmospheric influx of ${ }^{7} \mathrm{Be}$.

By the next survey in FebruaryMarch 1999 (Figure 11b), approximately one week before the event, the lake had destratified (in November 1998) and, with overturn, the inventory of ${ }^{7} \mathrm{Be}$ had been shared between water and sediments. The pattern does not resemble the long-term pattern of sediment accumulation (Figure 2b), which is centered within the HiDep area. However, there are isolated patchy sites with $\mathrm{FF}>1$, especially in the southeast corner.

The next survey, April-May 1999 (Figure 11c), took place about 1.8 months after the March event. The ${ }^{7} \mathrm{Be}$ deposited in the HiDep area on the day of the event would have decayed by approximately one half life (i.e., 50\%). Therefore, its contribution to subsequent deposition of ${ }^{7} \mathrm{Be}$ up to the survey time would be diminished. Nevertheless, the pattern of accumulation is quite consistent with the satellite plume in terms of its point of entry (southeast corner) and extension into the HiDep area. The pattern also consists of a swath of high FF values averaging about 1.5. Most notable, though, is that the primary resuspension event did not produce a highly focused pattern, which is characteristic of sediment accumulation. 
The last survey was made in June 1999 (Figure 11d), when the lake had been stratified for approximately one month and new additions of ${ }^{7} \mathrm{Be}$ to sediments were attenuated. The FF, which was largely a remnant of accumulations during March and April, began to resemble the long-term sediment accumulation pattern. The association of plume features with the ${ }^{7} \mathrm{Be}$ pattern seen in this study indicates that major resuspension events indeed convey additional ${ }^{7} \mathrm{Be}$ to HiDep sites. This occurs either by scavenging the radionuclide from water by local resuspension, or by recruitment and importation from sources outside the HiDep area.

\section{CIRCULATION AND SEDIMENT} TRANSPORT MODELS

During the EEGLE project, several numerical models of coastal circulation, wind waves, and sediment transport were used to study the turbidity plume events in Lake Michigan and to investigate the role of wind-induced circulation in the offshore transport of sedimentary material in Lake Michigan. Consistent with the radiotracer and trap studies discussed above, results from hydrodynamic circulation modeling experiments (Schwab, 1983) show that circulation in Lake Michigan is highly episodic as it is almost entirely wind-driven in early spring. The characteristic wind-driven circulation pattern in the lake consists of two counter-rotating gyres-a counterclockwise-rotating gyre to the right of the wind and a clockwise-rotating gyre to the left (Figure 12). The gyres are separated by a convergence zone along the downwind shore with resulting offshore flow and a divergence zone along the upwind shore with onshore flow.
This two-gyre circulation pattern with offshore flow was very clearly seen during a northerly wind event in March in southern Lake Michigan (Beletsky et al., 2003; Lee et al., 2007). The strongest sediment resuspension occurred in the southern lake and the shallow waters along the coastline because of the larger waves in southern Lake Michigan, which result from the dominant northerly wind in this early spring period.

A major goal of the EEGLE project was to collect detailed information during stormy and isothermal periods to enable the coupling of existing circulation models with dynamical transport of sediments and associated constituents. Several models were developed and implemented during the EEGLE project. Schwab et al. (2000) and Lou et al. (2000) developed a suspended sediment
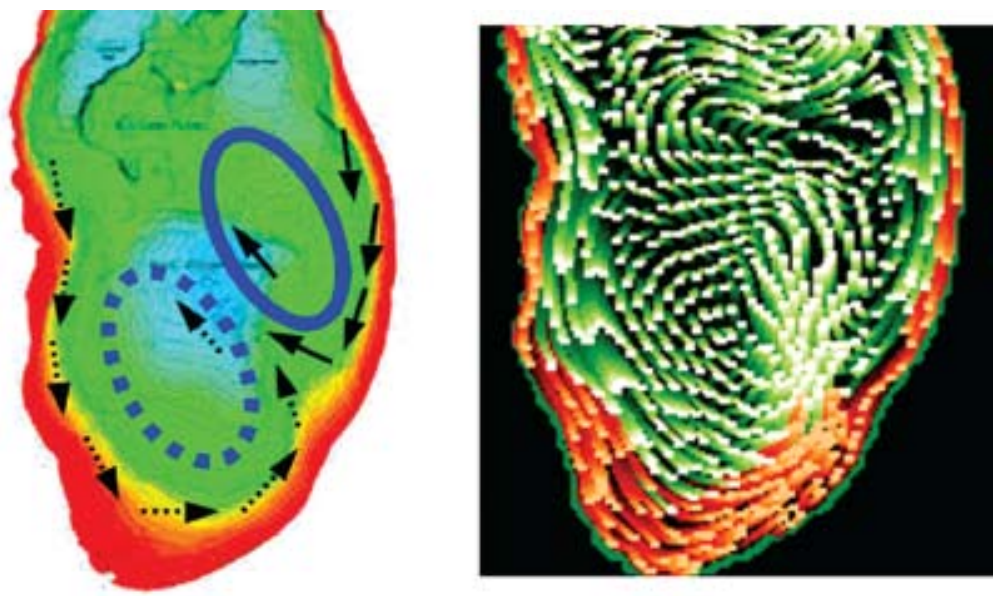

Figure 12. (Left panel) Schematic representation of two-gyre circulation pattern in southern Lake Michigan plotted over a bathymetric map of the lake. Northerly winds cause southward flow along the east and west shorelines. Southward-flowing currents converge on the southeast part of the shoreline and are directed offshore near the topographic ridge in this area. A counterclockwise gyre (dashed line) occupies the southwestern part of the basin and a clockwise gyre (solid line) occupies the northeastern part. (Right panel) Computer visualization of modeled circulation in southern Lake Michigan after the March 1998 wind event. Streaks represent paths of tracer particles, white for particles that started in deep water (>20 m) and orange for particles that started in shallow water $(<20 \mathrm{~m})$. The offshore flow associated with the ridge seen in the left panel is consistent with the region of maximum sediment accumulation (Figure 2). 
Michigan during November-December 1994 indicted that the model results were able to reproduce the general patterns of high-turbidity events in the lake. A simulation for the entire 1994-1995 twoyear period gave a reasonable description of sediment erosion/deposition in the lake, and it was consistent with sediment trap data. A simulation of the spring 1998 case by Schwab et al. (2000) agreed qualitatively with satellite imagery but failed to simulate the initial eddylike structure of the plume.

A multiple-sediment-type, threedimensional, hydrodynamic and sediment transport model was applied to Lake Michigan by Cardenas et al. (2005) to simulate conditions during the spring 2000 resuspension event. Model predictions were compared to data gathered by the EEGLE project, including turbidity and downward mass flux. The model predictions for turbidity compared well to observed data, especially in capturing the distinctive peaks in turbidity due to advection that occurred in the area of the resuspension feature. The advection peaks seemed tied to the presence of a highly resuspendible pool of sediments that was transported by weaker winds during early spring 2000. The model generally underestimated downward mass flux, though the predictions for the time intervals that included the time of peak winds and the following week were good to excellent. These intervals generally showed the highest downward mass flux. This work highlighted the importance of including multiple sediment types, with different associated critical shear stresses for resuspension, and the presence of a very easily resuspendible sediment layer in the model. The availability of a comprehensive data set was also important.
Based on the results of Cardenas et al. (2005), Lee et al. (2005) performed model sensitivity analysis to identify and compare quantitatively the important resuspension parameters in the coastal area of southern Lake Michigan. A one-dimensional resuspension and bed model capable of dealing with the type of mixed sediments (fine-grained + sand) common in the coastal area was developed and used to compare with measured suspended sediment concentrations. The results showed that the most sensitive parameters in the model were the fraction of fine-grained materials and the sediment availability. Other resuspension parameters such as settling velocity, critical shear stress, and erosion rate constant were also found to be important and may cause up to a $40 \%$ difference in suspended sediment concentration. Among those, the absolute magnitude of settling velocity is most crucial in controlling the first-order prediction.

A two-dimensional sediment transport model capable of simulating sediment resuspension of mixed (cohesive plus noncohesive) sediment was developed by Lee et al. (2007) and applied in order to quantitatively simulate the March 1998 resuspension event. Some characteristics of the model were the capability to incorporate several particle size classes, a physically based settling velocity formula, bed armoring, and sediment availability limitation. Important resuspension parameters were estimated from field and laboratory measurement data. The model reproduced the resuspension plume (observed by the Sea-viewing Wide Field Spectrometer [SeaWiFS] satellite and field instruments) and recently measured sedimentation rate distribution (using radiotracer techniques) fairly well. Figure 13 is an example of the comparison between model results and SeaWIFS remote sensing reflectance (RSR). Results were verified with field measurements of suspended sediment concentration and settling flux (by acoustic Doppler current profilers and sediment traps). Both wave conditions and sediment bed properties (critical shear stress, fine sediment fraction, and limited sediment availability or source) are the critical factors that determine the concentration distribution and width of the resuspension plume. The modeled sedimentation pattern shows preferential accumulation of sediment on the eastern side of the lake, which agrees with the observed sedimentation pattern despite a predominance of particle sources from the western shoreline. The main physical mechanisms determining the sedimentation pattern are (1) the two counterrotating circulation gyres producing offshore mass transport along the southeastern coast during northerly wind, and (2) the particle-settling velocity that controls the deposition location.

EEGLE data were used in another approach to modeling using the availability of turbidity maps derived from satellite imagery. Because satellite observations are synoptic, collected frequently, and highly resolved on geophysical scales, they can be a valuable source of information for development and application of numerical models. Although satellite data are used routinely with many types of operational atmospheric models, little work has been done to integrate satellite data with models of aquatic systems. Stroud et al. (in press) developed and examined schemes for 


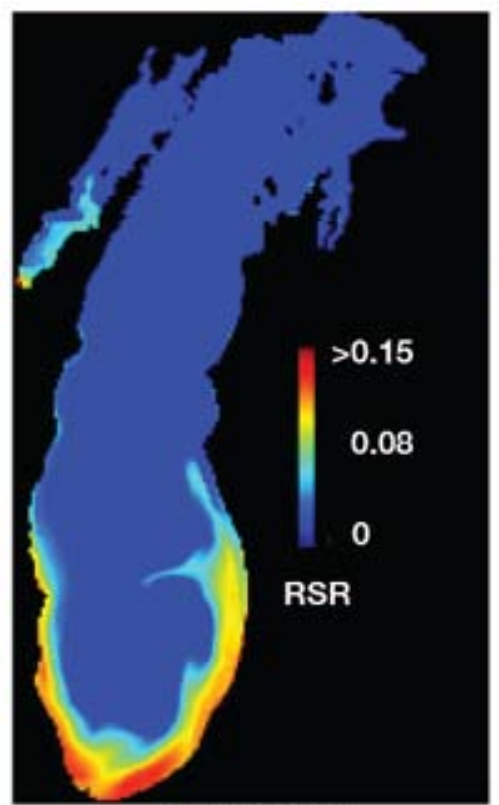

$3 / 24 / 9818 z$

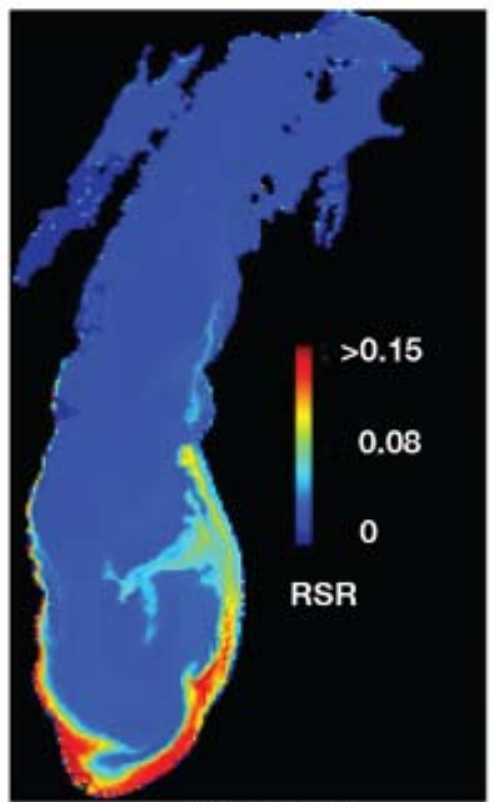

$3 / 24 / 9818 z$

Figure 13. Comparison of model-estimated remote sensing reflectance (RSR) (left panel) to SeaWiFS satellite-derived RSR (right panel) during the March-April 1998 resuspension event in Lake Michigan (Lee et al., 2007). All of the major features seen in the satellite image are simulated in the model output.

combining daily images obtained by the SeaWiFS satellite with a two-dimensional sediment transport model representing southern Lake Michigan. They performed a forecasting study focused on a two-month period in spring 1998 when a large storm caused substantial amounts of sediment resuspension and horizontal sediment transport in the lake. During the spring 1998 event, data assimilation schemes improved forecast root-meansquare-error (RMSE) by $40 \%$ over purely model-based approaches and by $20 \%$ over purely data-based approaches.

\section{SUMMARY}

The long hydraulic residence times of most large lakes, coupled with rapid sorption and settling of particleassociated constituents, results in large inventories of nutrients and trace contaminants in sediments. The EEGLE project allowed a group of researchers to explore the timing, frequency, duration, intensity, and subsequent consequences of intense storms, periods for which almost no data previously existed. These large events resuspend and transport materials from temporary sediment reservoirs to more permanent sinks with a small fraction becoming permanently incorporated annually into the complex sediment accumulation patterns of the depositional basins. The overall lake average time constant for this process is estimated to be 20 years; however, most of the redistribution occurs within a period of months to years, with much of the movement occurring during even shorter intervals. During these resuspension events, there is an opportunity for the lake to re-equilibrate with the constituents in the resuspendible pool of the sediments that represent years to decades of constituent loading. The EEGLE project has provided a rich database that will be mined for years to further incorporate the impact of major events into international management of the Great Lakes. [es

\section{REFERENCES}

Beletsky, D., D.J. Schwab, P.J. Roebber, M.J. McCormick, G.S. Miller, and J.H. Saylor. 2003. Modeling wind-driven circulation during the March 1998 sediment resuspension event in Lake Michigan. Journal of Geophysical Research 108(C2), 3038, doi:10.1029/2001JC001159.

Bloesch, J., and N.M. Burns. 1980. A critical review of sedimentation trap technique. Schweizerische Zeitschrift fur Hydrologie 42(1):16-55.

Bogden, J.J., J.W. Budd, B.J. Eadie, and K.C. Hornbuckle. 2002. The effect of a large resuspension event in southern Lake Michigan on the shortterm cycling of organic contaminants. Journal of Great Lakes Research 28:338-351.

Buesseler, K.O., A.E. Michaels, D.A. Siegel, and A.H. Knap. 1994. A three dimensional time dependent approach to calibrating sediment trap fluxes. Global Biogeochemical Cycles 8:179-193.

Cahill, R.A. 1981. Geochemistry of Recent Lake Michigan Sediments. Geological Survey Circular No. 517. Illinois State Geological Survey, Champaign, IL, 92 pp.

Cardenas, M.P., D.J. Schwab, B.J. Eadie, N. Hawley, and B.M. Lesht. 2005. Sediment transport model validation in Lake Michigan. Journal of Great Lakes Research 31:373-385.

Chambers, R.L., and B.J. Eadie. 1981. Nepheloid and suspended particulate matter in southeastern Lake Michigan. Sedimentology 28:439-447.

Chen, C., R. Ji, D.J. Schwab, D. Beletsky, G.L. Fahnenstiel, M. Jiang, T.H. Johengen, H. Vanderploeg, B.J. Eadie, J.W. Budd, and others. 2002. A model study of the coupled biological and physical dynamics in Lake Michigan. Ecological Modeling 152:145-168.

Colman, S.M., and D.M. Foster. 1994. A sediment budget for southern Lake Michigan: Source and sink models for different time intervals. Journal of Great Lakes Research 20:215-228.

Eadie, B.J., and J.A. Robbins. 1987. The role of particulate matter in the movement of contaminants in the Great Lakes. Pp. 319-364 in Sources and Fates of Aquatic Pollutants, ACS Advances in Chemistry Series No 216.

Eadie, B.J., and J.A. Robbins. 2005. Composition and accumulation of Lake Michigan sediments. Pp. 89-111 in The State of Lake Michigan. M. Munawar and T. Edsall, eds, Ecovision World Monograph Series, Aquatic Ecosystem Health and Management Society, Taylor and Francis, Philadelphia, PA.

Eadie, B.J., R.L. Chambers, W.S. Gardner, and G.L. 
Bell. 1984. Sediment trap studies in Lake Michigan: Resuspension and chemical fluxes in the southern basin. Journal of Great Lakes Research 10:307-321.

Eadie, B.J., D.J. Schwab, T.H. Johengen, P.J. Lavrentyev, G.S. Miller, R.E. Holland, G.A. Leshkevich, M.B. Lansing, N.R. Morehead, J.A. Robbins, N. Hawley, D.N. Edgington, and P.L. Van Hoof. 2002. Particle transport, nutrient cycling, and algal community structure associated with a major winter-spring sediment resuspension event in Southern Lake Michigan. Journal of Great Lakes Research 28:324-337.

Eadie, B.J., D.J. Schwab, G.A. Leshkevich, T.H. Johengen, R.A. Assel, N. Hawley, R.E. Holland, M.B. Lansing, P. Lavrentyev, G.S. Miller, N.R. Morehead, J.A. Robbins, and P.L. Van Hoof. 1996. Recurrent coastal plume in southern Lake Michigan. EOS Transactions of the American Geophysical Union 77:337-338.

Eadie, B.J., H.A. Vanderploeg, J.A. Robbins and G.L. Bell. 1989. The significance of sediment resuspension and particle settling. Pp. 196-209 in Large Lakes: Ecological Structure and Function. M.M. Tilzer and C. Serruya, eds, Springer Verlag.

Edgington, D.N., and J.A. Robbins. 1976. Patterns of deposition of natural and fallout radionuclides in the sediments of Lake Michigan and their relation to limnological processes. Pp. 705-729 in Environmental Biogeochemistry, J.O. Nriagu, ed., Ann Arbor Publishers.

Edgington, D.N., and J.A. Robbins. 1990. Time scales of sediment focusing in large lakes as revealed by measurements of fallout Cs-137. Pp. 210-223 in Large Lakes: Ecological Structure and Function. M.M. Tilzer, ed., Springer-Verlag, New York, NY.

Fahnenstiel, G.L., and D. Scavia. 1987. Dynamics of Lake Michigan phytoplankton: Primary production and growth. Canadian Journal of Fisheries and Aquatic Sciences 44:499-508.

Foster, D.S., and S.M. Colman. 1990. Distribution of postglacial deposits in Lake Michigan. USGS Map. Denver, CO.

Green, S. and B.J. Eadie. 2004. Introduction to special section: Transport and transformation of biogeochemically important materials in coastal waters. Journal of Geophysical Research 109(C10S01), doi:10.1029/2004JC002697.

Hawley, N., J. A. Robbins, and B.J. Eadie. 1986. The partitioning of 7-Beryllium in fresh water. Geochimica et Cosmochimica Acta 50:1,127-1,131.

Herdendorf, C.E. 1990. Distribution of the world's large lakes. Pp. 3-38 in Large Lakes: Ecological Structure and Function, M.M. Tilzer, ed., SpringerVerlag, Berlin.

Hornbuckle, K.C., G.L. Smith, S.M. Miller, B.J. Eadie, and M.B. Lansing. 2004. Magnitude and origin of polychlorinated biphenyl (PCB) and dichlorodiphenyltrichloroethand (DDT) compounds resuspended in southern Lake Michigan. Journal of Geophysical Research 109(C05017), doi:10.1029/2003JC001917.

Hough, J.L. 1958. Geology of the Great Lakes.
University of Illinois Press, Urbana, IL, 313 pp.

Ji, R., C. Chen, J.W. Budd, D.J. Schwab, D. Beletsky, G.L. Fahnenstiel, T.H. Johengen, H. Vanderploeg, B. Eadie, J. Cotner, W. Gardner, and M.H. Bundy. 2002. Influences of suspended sediments on the ecosystem in Lake Michigan: a 3-D coupled biophysical modeling experiment. Ecological Modeling 152:169-190.

Klump, J.V., K.W. Bedford, M.A. Donelan, B.J. Eadie, G.L. Fahnenstiel, and M.R. Roman. 1996. Coastal Ocean Processes (CoOP): Cross Margin Transport in the Great Lakes. NSF CoOP Report \#5, University of Maryland Technical Report TS-148, 133 pp.

Klump, J.V., D.N. Edgington, J.T. Waples, D.C. Szmania, B.E. Brown, and K.A. Orlandini. 2003. Sampling methods and approaches using radionuclide tracers in the study of sediment resuspension and cross margin transport in the nearshore of the Laurentian Great Lakes. International Journal of Sediment Resuspension 18(2):266-277.

Larson, G., and R. Schaetzl. 2001. Origin and evolution of the great lakes. Journal of Great Lakes Research 27:518-546.

Lee, C.-H., D.J. Schwab, and N. Hawley. 2005. Sensitivity analysis of sediment resuspension parameters in coastal area of southern Lake Michigan. Journal of Geophysical Research 110(C03004):16.

Lee, C.-H., D.J. Schwab, D. Beletsky, J. Stroud, and B.M. Lesht. 2007. Numerical modeling of mixed sediment resuspension, transport, and deposition during the March 1998 episodic events in southern Lake Michigan. Journal of Geophysical Research 112:(C02018), doi:10.1029/2005JC003419.

Lesht, B. 1989. Climatology of sediment transport on Indiana Shoals, Lake Michigan. Journal of Great Lakes Research 15:486-497

Lineback, J.A., and D.L. Gross. 1972. Depositional Patterns, Facies and Trace Element Accumulation in the Waukegan Member of the Late Pleistocene Lake Michigan Formation in Southern Lake Michigan, Studies in Lake Michigan Bottom Sediments. Number 10, Environmental Geology Notes, EGN Number 58, Illinois State Geological Survey, Urbana, IL, 25 pp.

Lou, J., D.J. Schwab, D. Beletsky, and N. Hawley. 2000. A model of sediment resuspension and transport dynamics in southern Lake Michigan. Journal of Geophysical Research 105(C3):6,591-6,610.

Moran, S.B., S.E. Weinstein, H.N. Edmonds, J.N. Smith, R.P. Kelly, M.E.Q. Pilson, and W.G. Harrison. 2003. Does ${ }^{234} \mathrm{Th} /{ }^{238} \mathrm{U}$ disequilibrium provide an accurate record of the export flux of particulate organic carbon from the upper ocean? Limnology and Oceanography 48:1,018-1,029.

Mortimer, C.H. 1988. Discoveries and testable hypotheses arising from coastal zone color scanner imagery of southern Lake Michigan. Limnology and Oceanography 33:203-226.

Muzzi, R.W., and B.J. Eadie. 2002. The design and performance of a sequencing sediment trap for lake research. Marine Technology Society Journal
36(2):23-28.

Parker, J.I., H.L. Conway, and E.M. Yaguchi. 1977. Dissolution of diatom frustules and recycling of amorphous silicon in Lake Michigan. Journal of Fisheries Research Board of Canada 34:545-551.

Rea, D.K., R.M. Owen, and P.A. Meyers. 1981. Sedimentary processes in the Great Lakes. Reviews of Geophysics and Space Physics 19:635-648.

Robbins, J.A. 1985. Great Lakes Regional Fallout Source Functions. NOAA Technical Memorandum ERL GLERL-56. NOAA Great Lakes Environmental Research Laboratory, Ann Arbor, MI.

Robbins, J.A., and B.J. Eadie. 1991. Seasonal cycling of trace elements, Cs-137, Be-7 and Pu-239+240 in Lake Michigan. Journal of Geophysical Research 96:17,081-17,104.

Robbins, J.A., and D.N. Edgington. 1975. Determination of recent sedimentation rates in Lake Michigan using Pb-210 and Cs-137. Geochimica et Cosmochimica Acta 39:285-304.

Robbins, J.A., and L.R. Herche. 1993. Radiochemical limnology: Models and uncertainty in ${ }^{210} \mathrm{~Pb}$ dating of sediments. Verhandlungen der Internationalen Vereinigung für Theoretische und Angewandte Limnologie 25:217-222.

Schwab, D.J. 1983. Numerical simulation of lowfrequency current fluctuations in Lake Michigan. Limnology and Oceanography 13(12):2,213-2,224.

Schwab, D. J., D. Beletsky, and J. Lou. 2000. The 1998 coastal turbidity plume in Lake Michigan. Estuarine, Coastal and Shelf Science 50:49-58.

Schwab, D.J., B.J. Eadie, R.A. Assel, and P.J. Roebber. 2006. Climatology of large sediment resuspension events in southern Lake Michigan. Journal of Great Lakes Research 32:50-62.

Smoak J.M., W.S. Moore, and R.C. Thunell. 2000. Influence of boundary scavenging and sediment focusing on ${ }^{234} \mathrm{Th},{ }^{228} \mathrm{Th}$ and ${ }^{210} \mathrm{~Pb}$ fluxes in the Santa Barbara basin. Estuarine Coastal and Shelf Science 51:373-384.

Stroud, J., B.M. Lesht, D.J. Schwab, D. Beletsky, and M.L. Stein. In press. Assimilation of satellite images into a numerical sediment transport model of Lake Michigan. Water Resources Research.

Vanderploeg, H.A., T.H. Johengen, P.J. Lavrentyev, C. Chen, G.A. Lang, M.A. Agy, M.H. Bundy, J.F. Cavaletto, B.J. Eadie, J.R. Liebig, and others. 2007. Anatomy of the recurrent coastal plume in Lake Michigan and its impacts on light climate, nutrients and plankton. Journal of Geophysical Research 112(C03S90), doi:10.1029/2004JC002379.

Waples J.T., K.A. Orlandini, D.N. Edgington, and J.V. Klump. 2004. Seasonal and spatial dynamics of ${ }^{234} \mathrm{Th} /{ }^{238} \mathrm{U}$ disequilibria in southern Lake Michigan. Journal of Geophysical Research 109(C10S06), doi:10.1029/2003JC002204. 